\title{
A randomized, controlled, double-blind trial of air vs carbon dioxide insufflation during ERCP
}

\author{
Evan S. Dellon, MD MPH ${ }^{1}$, Arumugam Velayudham, MD ${ }^{1}$, Bridger W. Clarke, MD ${ }^{1}$, Kim L. \\ Isaacs, MD PhD ${ }^{1}$, Lisa M. Gangarosa, MD ${ }^{1}$, Joseph A. Galanko, $\mathrm{PhD}^{1}$, and lan S. Grimm, \\ MD $^{1}$ \\ ${ }^{1}$ Center for Gastrointestinal Biology and Disease, Division of Gastroenterology and Hepatology, \\ Department of Medicine, University of North Carolina School of Medicine, Chapel Hill, NC
}

\section{Abstract}

Background: Visualization during gastrointestinal endoscopy requires distention of the bowel lumen. Carbon dioxide $\left(\mathrm{CO}_{2}\right)$ insufflation decreases post-procedure abdominal discomfort and distension after colonoscopy, but there have been few published studies on its use in endoscopic retrograde cholangiopancreatography (ERCP).

Objective: To assess the safety and efficacy of $\mathrm{CO}_{2}$ insufflation during ERCP.

Design: Double-blind, controlled, randomized trial

Setting: Tertiary care referral center.

Patients: Consecutive patients referred for ERCP, excluding those with known $\mathrm{CO}_{2}$ retention or taking chronic opiate medications.

Interventions: Insufflation of $\mathrm{CO}_{2}$ vs insufflation of air.

Main outcome measurements: Primary outcomes were abdominal pain assessed on a visual analogue scale, and abdominal distension. Secondary outcomes included transcutaneous $\mathrm{CO}_{2}$ levels $\left(\mathrm{pCO}_{2}\right)$ and procedural complications.

Results: 74 patients were analyzed, 38 in the air group and 36 in the $\mathrm{CO}_{2}$ group. Pain scores were similar in both groups one-hour post-procedure $\left(16 \mathrm{vs} 11 \mathrm{~mm}\right.$ in the $\mathrm{CO}_{2}$ and air groups, respectively; $\mathrm{p}=0.29$ ), as well as over the subsequent 24 hours. There were also no significant differences between groups in abdominal distension or $\mathrm{pCO}_{2}$ levels. There were 13 patients with complications in the air group and 5 in the $\mathrm{CO}_{2}$ group ( $\mathrm{p}=0.04$; nominal significance removed by Bonferroni correction), though most were minor in nature.

Limitations: Single center.

(C) 2010 American Society for Gastrointestinal Endoscopy. Published by Mosby, Inc. All rights reserved. Corresponding Author: Evan S. Dellon MD CB\#7080 Bioinformatics Building 130 Mason Farm Rd. UNC-CH Chapel Hill, NC 27599-7080 Phone: (919) 966-2513 Fax: (919) 843-2508 edellon@ med.unc.edu.

Publisher's Disclaimer: This is a PDF file of an unedited manuscript that has been accepted for publication. As a service to our customers we are providing this early version of the manuscript. The manuscript will undergo copyediting, typesetting, and review of the resulting proof before it is published in its final citable form. Please note that during the production process errors may be discovered which could affect the content, and all legal disclaimers that apply to the journal pertain.

Selected data from this paper were presented during DDW 2009.

Clinicaltrials.gov \# NCT00685386 
Conclusions: The use of $\mathrm{CO}_{2}$ for insufflation during ERCP was safe in a tertiary care referral population. However, use of $\mathrm{CO}_{2}$ during ERCP did not lead to decreased post-procedural pain or less abdominal distension, so its role in this procedure remains in question.

\section{Keywords}

Endoscopic retrograde cholangiopancreatography; carbon dioxide; randomized clinical trial; endoscopy; capnography

\section{Introduction}

Adequate visualization during gastrointestinal endoscopy requires distention of the bowel lumen. While it is standard practice in the United States to use ambient, or "room" air for this purpose, there are potential disadvantages. After insufflation, air is not absorbed and must be passed from the GI tract, which can lead to bowel distension and abdominal discomfort. Carbon dioxide $\left(\mathrm{CO}_{2}\right)$ has been previously suggested as an alternative to air, ${ }^{1-7}$ and subsequent studies have examined its safety and efficacy as compared to air. ${ }^{8-19}$ Results have been consistent, particularly in colonoscopy but also with flexible sigmoidoscopy and double-balloon enteroscopy, that the use of $\mathrm{CO}_{2}$ insufflation leads to less post-procedural abdominal pain and distension. ${ }^{20}$ The explanation for this is that $\mathrm{CO}_{2}$ is rapidly absorbed from the bowel, thus allowing the bowel to deflate quickly and decreasing patient discomfort.

Though the use of $\mathrm{CO}_{2}$ for endoscopic retrograde cholangiopancreatography (ERCP) has been less well studied, two recent randomized control trials suggested that patients experienced less pain and distention with $\mathrm{CO}_{2}$ as compared to air. ${ }^{18,19}$ Because ERCP is arguably the endoscopic procedure with the highest risk of complications, ${ }^{21,}{ }^{22}$ and because ERCP can be a longer procedure with higher doses of sedation medications administered and potentially greater amount of air insufflated, it is an attractive candidate for $\mathrm{CO}_{2}$ use. However, questions remain about the safety and efficacy of $\mathrm{CO}_{2}$ insufflation during ERCP.

The aims of this randomized, controlled, double-blind trial were to assess the safety, as measured by transcutaneous partial arterial pressure of $\mathrm{CO}_{2}\left(\mathrm{pCO}_{2}\right)$ levels, and efficacy, as measured by post-procedural abdominal pain and distention, of $\mathrm{CO}_{2}$ insufflation during ERCP. We hypothesized that $\mathrm{CO}_{2}$ insufflation would be as safe as air insufflation, and that it would be associated with less post-procedural abdominal pain and distension.

\section{Methods}

\section{Participants}

Between June 2008 and January 2009, all consecutive adult patients undergoing ERCP at University of North Carolina (UNC) Hospitals GI procedures unit were screened for recruitment. Patients were excluded if they: were $\leq 18$ years old; had chronic obstructive pulmonary disease (COPD) requiring oxygen; had known $\mathrm{CO}_{2}$ retention (defined as diagnosed in the medical record); had a same-day second endoscopy that would require additional bowel insufflation; required general anesthesia for the procedure; used chronic opiates for pain (defined as the use of a long-acting opiate at least daily for greater than 45 days); were unable to read or understand English; were pregnant; were incarcerated, or had any medical instability making the procedure unsafe. All participants provided informed consent prior to study enrollment. 


\section{Randomization and blinding}

Randomization was 1:1 by variable block size using a computer-generated sequence.

Allocation was concealed with opaque envelopes. A research nurse not involved with patient recruitment or data collection determined assignment and masked the equipment. The procedure room set-up was the same for every study procedure regardless of gas used. Both the $\mathrm{CO}_{2}$ insufflator (see below) and the air button and indicator on the scope processor were covered so the settings and type of gas being insufflated could not be determined. All patients were tracked with a unique identifier unrelated to their treatment assignment. Overall, patients, endoscopists, ERCP nurses, and recovery nurses, as well as the data collectors and analysts (for the initial analysis) were all blinded as to study status.

\section{ERCP, $\mathrm{CO}_{2}$ insufflation, and capnography}

ERCP and patient monitoring were performed as per standard protocol at our center. Conscious sedation with fentanyl and midazolam was administered. The procedure was performed at the discretion of the endoscopist as dictated by the clinical indication and findings. For the intervention, patients either received standard air insufflation through the scope processor, or $\mathrm{CO}_{2}$ insufflation.

$\mathrm{CO}_{2}$ was insufflated using the Olympus Endoscopic $\mathrm{CO}_{2}$ Regulation Unit (UCR, Olympus Medical, Central Valley, PA; Figure 1A), an FDA-approved device. This unit connects to a $\mathrm{CO}_{2}$ tank and dispenses $\mathrm{CO}_{2}$ through the gas outlet on the front of the machine. In turn, this connects to a specialized water bottle lid (Figure 1B) that also has a standard adaptor for attaching the water bottle to the scope (Figure 2). The flow rate of $\mathrm{CO}_{2}$ is designed to be similar to the flow rate of air when the processor is set on "high", so the endoscopist does not detect a difference at the level of the air button. The insufflator was turned on for all procedures and is essentially silent; when it is activated to deliver flow, there is no appreciable additional noise.

Transcutaneous capnography was performed using the TOSCA 500 monitor (Radiometer America Inc., Westlake, OH). This non-invasive monitor was selected because it has previously been shown to measure the $\mathrm{pCO}_{2}$ with outstanding accuracy as compared with blood gas assessment. ${ }^{23,} 24$

\section{Outcomes}

The primary outcomes were abdominal pain, as recorded on a $100 \mathrm{~mm}$ visual analogue scale (VAS) and measured pre- and 1, 3,6, and 24-hours post-ERCP, and abdominal girth as measured at the level of the umbilicus pre- and immediately post-ERCP (defined as when the patient was transferred from fluoroscopy table to stretcher) by a research assistant blinded to allocation. These time frames were picked for comparison to previously conducted studies in the field. ${ }^{9}, 11,12,16,{ }^{18}$ The 1-hour post-procedure time point was the main outcome of interest overall, and was assessed post-procedure either in the recovery area, in the waiting room for patients who were already discharged, or on the hospital ward for inpatients. Patients were given a form with the pain scales for the 3,6, and 24 hour time points and returned them via mail. All patients were contacted approximately 24 hours post-procedure to assess for complications.

The main secondary outcomes were transcutaneous pCO2 levels (baseline, maximum, and mean), and procedural complications. Complications included: respiratory depression requiring reversal agents; $\mathrm{CO}_{2}$ retention with $\mathrm{pCO}_{2}>55$; hypotension requiring fluid boluses, reversal agents, or pressors; cardiac arrhythmias; immediate and delayed bleeding (defined as requiring endoscopic intervention for hemostasis); cholangitis; pancreatitis (defined by standard conventions25); perforation; and death. Delayed complications were assessed with a follow-up phone call 24 hours post-procedure. Other outcomes of interest included time to 
discharge from the recovery room, procedure costs as measured by billing charges, medication doses, time to cannulation (measured as time from cannula deployment to fluoroscopy confirmed cannulation), cannulation success rate, total ERCP time, and procedure success rate. Intra- and post-procedure data collection was performed by a research assistant or the lead author, all of whom were blinded as to patient allocation.

Data were also collected for other factors of interest such as patient demographics, body mass index (BMI), ERCP indication, final diagnosis, whether the patient had undergone a prior ERCP, comorbidities, surgical history, and, for procedures in which a fellow was involved, the fellow experience level (prior number of ERCPs).

\section{Statistical analysis}

Analyses were performed on an intention-to-treat basis for patients who received the intervention. Data analysts were unmasked as to treatment assignment only after data collection, editing for quality, and initial analysis (using blinded study groups) were complete. Characteristics of the study groups were compared with a t-test for continuous variables and chi-square (or Fisher's exact test, when appropriate) for categorical variables. General estimating equations (GEE) were used to analyze the serial pain scores as repeated measures over time. Multiple linear regression was used to adjust for potential confounding factors. Statistical significance was taken as $\mathrm{p}<0.05$. In recognizing that there were several statistical tests performed on some outcome data arising from individual patients, the uncorrected pvalues are presented along with the effect of correction utilizing the method of Bonferroni whenever that correction would remove statistical significance at the $p<0.05$ level. All analyses were performed with Stata version 9 (StataCorp, College Station, TX).

Sample size was determined by power calculation. We aimed to detect what we felt would be a clinically significant difference in the primary outcome of 1-hour post-procedure abdominal pain, specifically a $20 \mathrm{~mm}$ decrease in the VAS. Based on data available at the time of study design, $6,9,11,12,16,18$ we estimated that the room air group would have a mean VAS of $40 \mathrm{~mm}$ and the $\mathrm{CO}_{2}$ group would have a mean score of $20 \mathrm{~mm}$. To detect this difference with a power of 0.9 and alpha of 0.05 , complete data would be required on at least 33 patients per group, so assuming drop-out, our recruitment goal was 74 patients total.

This study was approved by the UNC Institutional Review Board. It was an investigatorinitiated trial, funded in part by Olympus. Study design and reporting complied with the CONSORT statement. ${ }^{26}$ This trial was registered at www.clinicaltrials.gov (NCT00685386).

\section{Results}

\section{Patient and ERCP characteristics}

Of the 157 patients assessed for eligibility, 78 patients were randomized and 74 were included in data analysis (Figure 3). Three of the four patients not included were found to be ineligible after randomization (they were undergoing a second endoscopic procedure that day); technical difficulties precluded patient participation in the other procedure.

The baseline characteristics were similar across the study groups, including demographics, BMI, comorbidities, previous surgeries, and the proportion of patients who had undergone prior ERCP (Table 1).

ERCP indications were also similar in both study groups, as was the proportion of cases in which a GI fellow was involved and the number of cases in which sphincterotomy was performed (Table 2). The most common ERCP indications were choledocholithiasis, pancreatitis, and abnormal LFTs. While there were trends towards some differences between 
the groups, for example more stents were placed in the air group (34\% vs $19 \%$ in the $\mathrm{CO}_{2}$ group), there were more normal cholangiograms in the air group ( $16 \%$ vs $6 \%$ in the $\mathrm{CO}_{2}$ group), and there was less choledocholithiasis in the air group ( $21 \%$ vs $42 \%)$, these were not statistically significant.

\section{Abdominal pain and distension}

For the primary outcome of abdominal pain, there were no significant differences in baseline scores (Table 3). One-hour post-procedure, the pain score was slightly higher in the $\mathrm{CO}_{2}$ group as compared to the air group ( $16 \mathrm{vs} 11 \mathrm{~mm} ; \mathrm{p}=0.29$ ). Over the following 24 hours, there were also no significant differences in pain scores at any of the individual time points, or when considered as measurements over time on GEE analysis $(p=0.52$; Figure 4$)$.

For abdominal distension, there were no significant differences between the two groups before or after ERCP, and abdominal girth did not change appreciably in either group; there was a mean increase in girth in both groups of just under $1 \mathrm{~cm}(\mathrm{p}=0.96$; Table 3$)$.

\section{$\mathrm{CO}_{2}$ levels and complications}

For $\mathrm{pCO}_{2}$ levels, the groups were approximately equal at baseline at $40 \mathrm{mmHg}$ (Table 3). Patients in both the air and $\mathrm{CO}_{2}$ group had an increase in $\mathrm{pCO}_{2}$ during the procedure, with the air group having slightly higher maximum levels ( $50 \mathrm{vs} 49 \mathrm{mmHg}$ ), but these were not statistically significant $(\mathrm{p}=0.56)$.

Overall, there were 13 patients with complications in the air group and 5 in the $\mathrm{CO}_{2}$ group (p $=0.04$; nominal significance removed by correction for multiple testing of data; Table 3 ), though most of these were minor. Two of the complications in the air group were related to respiratory depression and required reversal agents; there were no respiratory events in the $\mathrm{CO}_{2}$ group. There were 8 patients in the air group and 5 in the $\mathrm{CO}_{2}$ group that reached the complication threshold of $\mathrm{pCO}_{2}>55$. Rates of pancreatitis were approximately the same between the groups.

\section{Other outcomes}

While the mean fentanyl dose was similar between groups, the midazolam dosing was somewhat higher in the air group ( $11 \mathrm{vs} 9 \mathrm{mg} ; \mathrm{p}=0.08$; Table 3 ). Cannulation rate was similar between the groups, but cannulation time was longer in the $\mathrm{CO}_{2}$ group ( 8 vs 4 minutes; $\mathrm{p}=$ $0.05)$; total procedure times were similar between the two groups. The mean time to discharge from recovery was almost 12 minutes shorter in the $\mathrm{CO}_{2}$ group than in the air group (67 vs 79 minutes), but this was not statistically significant $(\mathrm{p}=0.12)$. Finally, there was no difference between groups in the cost of the procedure.

\section{Discussion}

$\mathrm{CO}_{2}$ insufflation during ERCP seems logical. Because procedure times can be long and sedation doses high, there may be greater volumes of gas insufflated required to maintain visualization of the lumen. We performed a randomized, double-blind, controlled trial to assess the safety and efficacy of $\mathrm{CO}_{2}$ insufflation during ERCP. Based on prior literature, we expected $\mathrm{CO}_{2}$ insufflation to be safe and associated with decreased post-procedural abdominal pain and distension as compared to air insufflation. Our results, however, showed that while $\mathrm{CO}_{2}$ was safe to use, there were no significant differences between the air and the $\mathrm{CO}_{2}$ group for the primary outcomes of abdominal pain and distension. This is in contrast to two recent clinical trials examining the same issue. 
In the first trial, ${ }^{18}$ Bretthauer and colleagues randomized 118 patients to either air or $\mathrm{CO}_{2}$ insufflation for ERCP. Patients with COPD were excluded, and midazolam with or without pethidine was used for sedation. Abdominal pain was measured with a $100 \mathrm{~mm}$ VAS before and 1, 3, 6, and 24-hours post-procedure, abdominal distension was assessed by abdominal xray, and transcutaneous $\mathrm{pCO}_{2}$ levels were measured in 62 patients. In the second trial, ${ }^{19}$ Maple and colleagues randomized 100 patients to the same intervention, but used propofol for sedation. They also excluded patients with COPD as well as those with significant preprocedure pain. Abdominal pain was measured with a 10 point VAS before the procedure, on arrival to recovery, on discharge, and approximately 24-48 hours post-procedure. Abdominal girth was measured directly, but $\mathrm{pCO}_{2}$ levels were not recorded. Despite the methodologic differences in these studies and the use of different $\mathrm{CO}_{2}$ insufflation devices, the results were similar: there was less pain and distension in the $\mathrm{pCO}_{2}$ group as compared to the air group.

How can we interpret the results from our study in the context of the two prior ERCP trials, as well as the findings from trials of other endoscopic modalities? $6,9-12,16-18,20,27$ There are several possibilities. First, we detected a smaller than expected effect size. The study was powered for pain scores in the $20-40 \mathrm{~mm}$ range, with a $20 \mathrm{~mm}$ decrease in VAS which we felt would be clinically meaningful, not the $10-20 \mathrm{~mm}$ range that we observed, with score changes of 5-10 mm. Second, pain-assessment 1-hour post-ERCP may have been too soon given the midazolam and fentanyl doses administered. In particular, doses of midazolam were higher in the air group, and this may explain the lower than expected 1-hour scores in that group. The sedation protocol is a major difference between our study and that of Maple and colleagues. Third, variation in measurement of abdominal girth may have obscured differences between the study groups, particularly when previously reported differences are on the magnitude of $2-3 \mathrm{~cm} .{ }^{19}$

Because of these reasons, and because it was possible that our heterogenous patient population could mask an effect in subgroups, we performed a sensitivity analysis. However, regardless of whether we stratified by a biliary or pancreatic indication for ERCP, by baseline pain score, by presence of post-ERCP pancreatitis, or if we controlled for possible confounding factors, we did not detect a difference in outcomes. Therefore, because we feel the design of this trial was methodologically sound, it appears that $\mathrm{CO}_{2}$ insufflation was not effective for decreasing abdominal pain or distension in our population of unselected patients undergoing ERCP for a wide range of indications at a tertiary care referral center.

There are several other findings of note in our study, however. First, we generated safety data and $\mathrm{pCO}_{2}$ levels on all patients in the study and showed that $\mathrm{CO}_{2}$ insufflation was well tolerated. Because $\mathrm{pCO}_{2}$ levels rose in both groups, the increase was likely attributable to the effect of sedation, rather than to the effect of $\mathrm{CO}_{2}$ insufflation. Moreover, as compared to almost all prior studies, we did not exclude all patients with COPD or obstructive sleep apnea from participating. This is important information which speaks to the tolerability of $\mathrm{CO}_{2}$ insufflation in patients with comorbidities. In addition, while $\mathrm{CO}_{2}$ monitoring during ERCP with air insufflation has been shown to decrease respiratory complications, ${ }^{28}$ given the safety data we have presented, we do not feel $\mathrm{CO}_{2}$ insufflation in and of itself would require routine capnography. A final point is that though not statistically significant, time to discharge from recovery was somewhat shorter in the $\mathrm{CO}_{2}$ group, and future studies could address in more detail whether $\mathrm{CO}_{2}$ insufflation could impact the efficiency of GI procedure units where fentanyl and midazolam are used.

In conclusion, the use of $\mathrm{CO}_{2}$ for insufflation during ERCP was safe in a heterogenous tertiary care referral population. The mild rise we observed in $\mathrm{pCO}_{2}$ in both groups was not attributable to $\mathrm{CO}_{2}$ insufflation, but rather to conscious sedation. We feel that this is the most extensive safety data using $\mathrm{pCO}_{2}$ levels reported to date for use of $\mathrm{CO}_{2}$ in $\mathrm{GI}$ endoscopy, and in contrast 
to other studies, we included patients with pulmonary disease. Finally, because use of $\mathrm{CO}_{2}$ during ERCP did not lead to decreased post-procedural pain or less abdominal distension, which were the primary outcomes of this study, its role in this procedure for these purposes remains in question.

\section{Acknowledgments}

Grant support: This work was funded, in part, by an investigator-initiated grant from Olympus which was used for research coordinator support and to purchase the transcutaneous capnograph; Olympus also provided the $\mathrm{CO}_{2}$ insufflator unit. It was also supported, in part, by KL2RR025746 from the National Center for Research Resources and by National Institutes of Health training grant T32 DK007634

\section{ABBREVIATION PAGE}

$\begin{array}{ll}\mathrm{BMI} & \text { body mass index } \\ \mathrm{CO}_{2} & \text { carbon dioxide } \\ \mathrm{COPD} & \text { chronic obstructive pulmonary disease } \\ \mathrm{ERCP} & \text { endoscopic retrograde cholangiopancreatography } \\ \mathrm{GEE} & \text { general estimating equation } \\ \mathrm{pCO}_{2} & \text { partial arterial pressure of } \mathrm{CO}_{2} \\ \mathrm{UNC} & \text { University of North Carolina } \\ \mathrm{VAS} & \text { visual analogue scale }\end{array}$

\section{References}

1. Brandt LJ, Boley SJ, Sammartano R. Carbon dioxide and room air insufflation of the colon. Effects on colonic blood flow and intraluminal pressure in the dog. Gastrointest Endosc 1986;32:324-9. [PubMed: 3095168]

2. Hussein AM, Bartram CI, Williams CB. Carbon dioxide insufflation for more comfortable colonoscopy. Gastrointest Endosc 1984;30:68-70. [PubMed: 6425108]

3. Phaosawasdi K, Cooley W, Wheeler J, Rice P. Carbon dioxide-insufflated colonoscopy: an ignored superior technique. Gastrointest Endosc 1986;32:330-3. [PubMed: 3095169]

4. Rogers BH. Carbon dioxide for colonoscopy. Gastroenterology 1980;78:1659-60. [PubMed: 6768639]

5. Rogers BH. CO2 during colonoscopy for safety and comfort. Gastrointest Endosc 1985;31:108-9. [PubMed: 3922846]

6. Stevenson GW, Wilson JA, Wilkinson J, Norman G, Goodacre RL. Pain following colonoscopy: elimination with carbon dioxide. Gastrointest Endosc 1992;38:564-7. [PubMed: 1397911]

7. Williams CB. Who's for CO2? Gastrointest Endosc 1986;32:365-7. [PubMed: 3095172]

8. Bretthauer M, Hoff G. The use of CO2 in colonoscopy. Gastrointest Endosc 2003;57:436-7. author reply 437-8. [PubMed: 12612542]

9. Bretthauer M, Hoff G, Thiis-Evensen E, Grotmol T, Holmsen ST, Moritz V, et al. Carbon dioxide insufflation reduces discomfort due to flexible sigmoidoscopy in colorectal cancer screening. Scand J Gastroenterol 2002;37:1103-7. [PubMed: 12374237]

10. Bretthauer M, Hoff GS, Thiis-Evensen E, Huppertz-Hauss G, Skovlund E. Air and carbon dioxide volumes insufflated during colonoscopy. Gastrointest Endosc 2003;58:203-6. [PubMed: 12872086]

11. Bretthauer M, Lynge AB, Thiis-Evensen E, Hoff G, Fausa O, Aabakken L. Carbon dioxide insufflation in colonoscopy: safe and effective in sedated patients. Endoscopy 2005;37:706-9. [PubMed: 16032487]

12. Bretthauer M, Thiis-Evensen E, Huppertz-Hauss G, Gisselsson L, Grotmol T, Skovlund E, et al. NORCCAP (Norwegian colorectal cancer prevention): a randomised trial to assess the safety and 
efficacy of carbon dioxide versus air insufflation in colonoscopy. Gut 2002;50:604-7. [PubMed: 11950803]

13. Nakajima K, Lee SW, Sonoda T, Milsom JW. Intraoperative carbon dioxide colonoscopy: a safe insufflation alternative for locating colonic lesions during laparoscopic surgery. Surg Endosc 2005;19:321-5. [PubMed: 15645328]

14. Nakajima K, Yasumasa K, Endo S, Takahashi T, Nishitani A, Nezu R, et al. A versatile dual-channel carbon dioxide (CO2) insufflator for various $\mathrm{CO} 2$ )applications. The prototype. Surg Endosc 2006;20:334-8. [PubMed: 16362477]

15. Saito Y, Uraoka T, Matsuda T, Emura F, Ikehara H, Mashimo Y, et al. A pilot study to assess the safety and efficacy of carbon dioxide insufflation during colorectal endoscopic submucosal dissection with the patient under conscious sedation. Gastrointest Endosc 2007;65:537-42. [PubMed: 17321264]

16. Sumanac K, Zealley I, Fox BM, Rawlinson J, Salena B, Marshall JK, et al. Minimizing postcolonoscopy abdominal pain by using $\mathrm{CO}(2)$ insufflation: a prospective, randomized, double blind, controlled trial evaluating a new commercially available $\mathrm{CO}(2)$ delivery system. Gastrointest Endosc 2002;56:190-4. [PubMed: 12145595]

17. Church J, Delaney C. Randomized, controlled trial of carbon dioxide insufflation during colonoscopy. Dis Colon Rectum 2003;46:322-6. [PubMed: 12626906]

18. Bretthauer M, Seip B, Aasen S, Kordal M, Hoff G, Aabakken L. Carbon dioxide insufflation for more comfortable endoscopic retrograde cholangiopancreatography: a randomized, controlled, doubleblind trial. Endoscopy 2007;39:58-64. [PubMed: 17252462]

19. Maple JT, Keswani RN, Hovis RM, Saddedin EZ, Jonnalagadda S, Azar RR, et al. Carbon dioxide insufflation during ERCP for reduction of postprocedure pain: a randomized, double-blind, controlled trial. Gastrointest Endosc 2009;70:278-83. [PubMed: 19523621]

20. Dellon ES, Hawk JS, Grimm IS, Shaheen NJ. The use of carbon dioxide for insufflation during GI endoscopy: a systematic review. Gastrointest Endosc 2009;69:843-9. [PubMed: 19152906]

21. Adler DG, Baron TH, Davila RE, Egan J, Hirota WK, Leighton JA, et al. ASGE guideline: the role of ERCP in diseases of the biliary tract and the pancreas. Gastrointest Endosc 2005;62:1-8. [PubMed: 15990812]

22. Mallery JS, Baron TH, Dominitz JA, Goldstein JL, Hirota WK, Jacobson BC, et al. Complications of ERCP. Gastrointest Endosc 2003;57:633-8. [PubMed: 12709688]

23. Eberhard P, Gisiger PA, Gardaz JP, Spahn DR. Combining transcutaneous blood gas measurement and pulse oximetry. Anesth Analg 2002;94:S76-80. [PubMed: 11900043]

24. Rohling R, Biro P. Clinical investigation of a new combined pulse oximetry and carbon dioxide tension sensor in adult anaesthesia. J Clin Monit Comput 1999;15:23-7. [PubMed: 12578058]

25. Cotton PB, Lehman G, Vennes J, Geenen JE, Russell RC, Meyers WC, et al. Endoscopic sphincterotomy complications and their management: an attempt at consensus. Gastrointest Endosc 1991;37:383-93. [PubMed: 2070995]

26. Moher D, Schulz KF, Altman D. The CONSORT statement: revised recommendations for improving the quality of reports of parallel-group randomized trials. JAMA 2001;285:1987-91. [PubMed: 11308435]

27. Domagk D, Bretthauer M, Lenz P, Aabakken L, Ullerich H, Maaser C, et al. Carbon dioxide insufflation improves intubation depth in double-balloon enteroscopy: a randomized, controlled, double-blind trial. Endoscopy 2007;39:1064-7. [PubMed: 18072057]

28. Qadeer MA, Vargo JJ, Dumot JA, Lopez R, Trolli PA, Stevens T, et al. Capnographic monitoring of respiratory activity improves safety of sedation for endoscopic cholangiopancreatography and ultrasonography. Gastroenterology 2009;136:1568-76. quiz 1819-20. [PubMed: 19422079] 


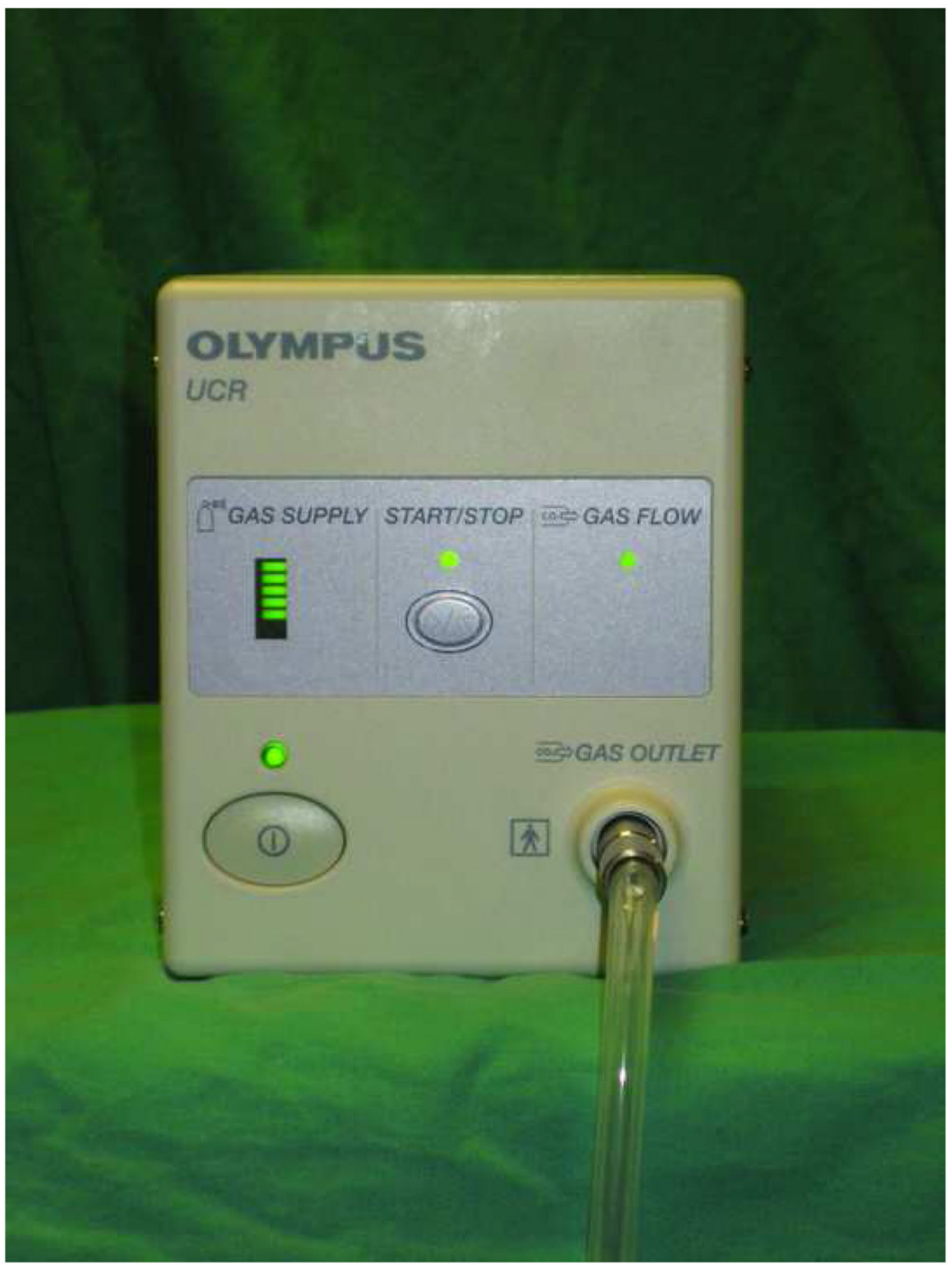




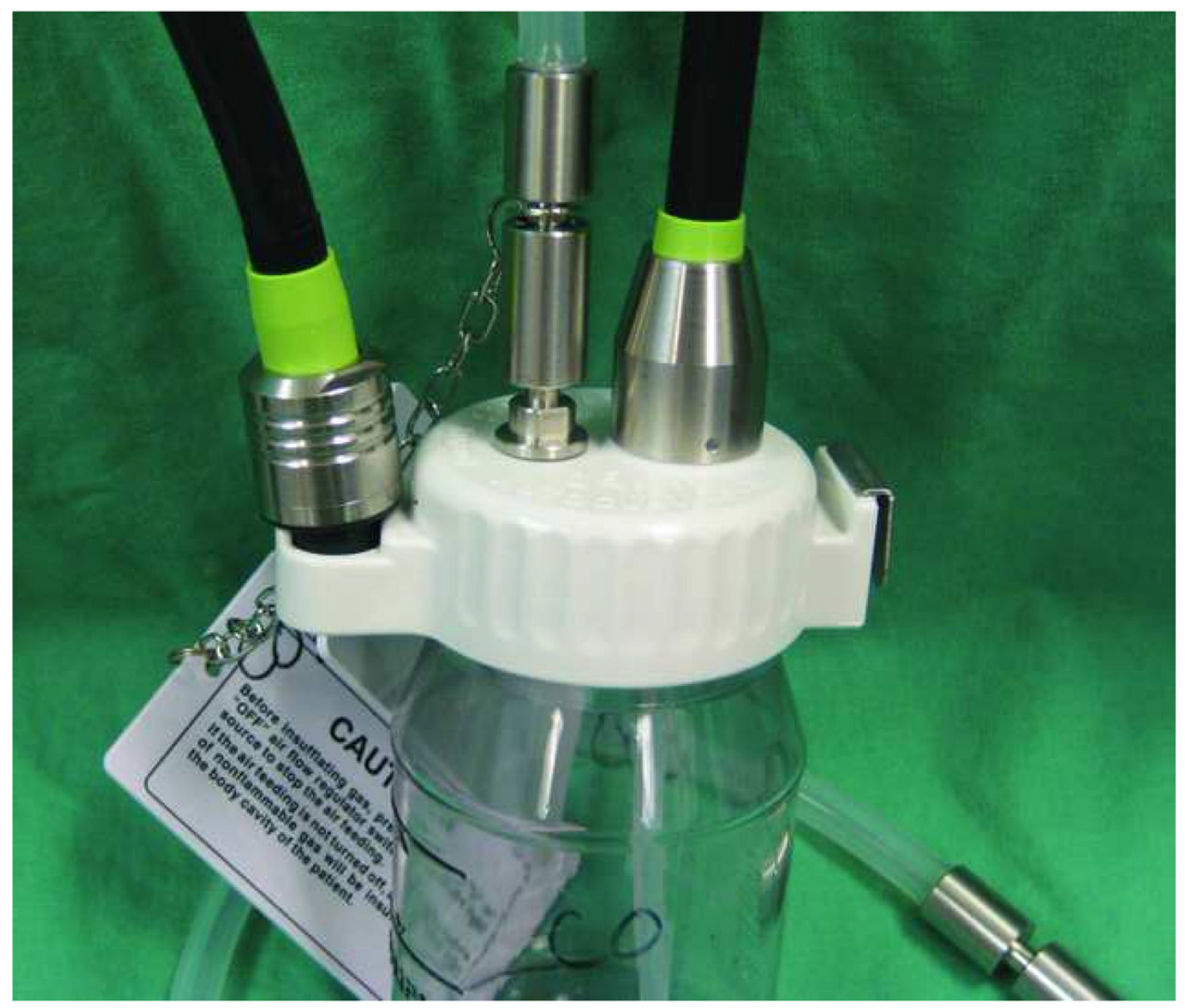

Figure 1.

(A) The Olympus UCR Endoscopic $\mathrm{CO}_{2}$ Regulation Unit (UCR, Olympus Medical, Central Valley, PA. There is a power button (lower left side), a gas supply indicator lamp, a button in the center of the device that starts and stops the flow of $\mathrm{CO}_{2}$, and a gas flow indicator. The back of this unit connects to a $\mathrm{CO}_{2}$ tank, and $\mathrm{CO}_{2}$ is dispensed through the gas outlet on the lower right side of the front of the machine. This, in turn, connects to the lid of a specialized water bottle (B) that also has a standard adaptor which connects the water bottle to the scope. 


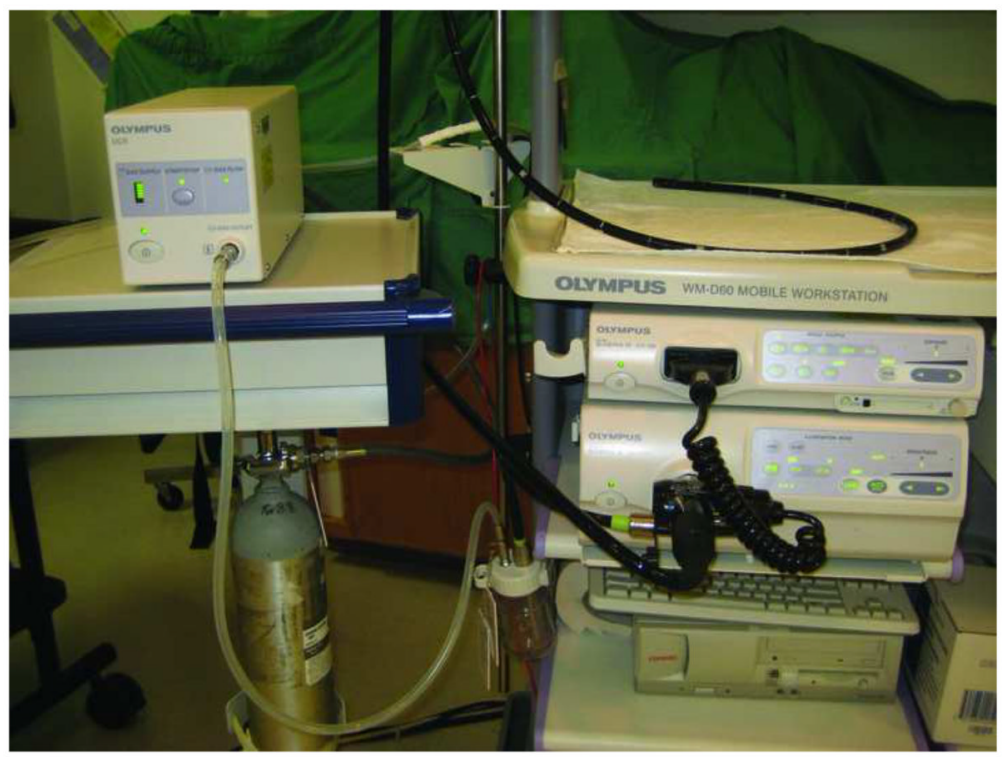

Figure 2.

The study set up. The $\mathrm{CO}_{2}$ insufflator is connected to the $\mathrm{CO}_{2}$ tank as well as to the specialized water bottle lid. For all cases in the study, both the insufflator and the air indicator on the scope processor were completely covered in order to mask treatment assignment. 


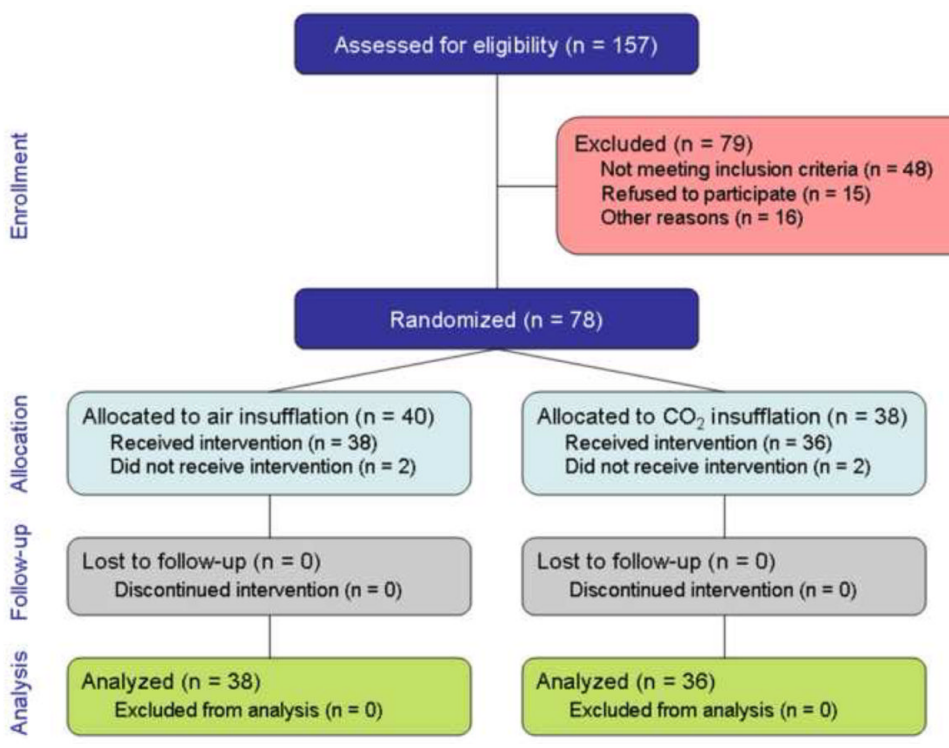

Figure 3.

CONSORT patient flow diagram. Of the patients not meeting inclusion criteria, 2 were known $\mathrm{CO}_{2}$ retainers, 6 were unable to provide consent due to dementia, 9 were medically unstable, 5 required general anesthesia, 9 were on chronic opioids, 4 were non-English speaking, 4 were $<18$ years old, 3 had Billroth II post-surgical anatomy precluding use of the duodenoscope, 1 was incarcerated, and 5 were scheduled for other non-ERCP procedures. The 16 cases excluded for other reasons included 5 patients who were screened but did not come for their appointment, and 11 patients who were missed for recruitment. Of the 4 patients who were randomized but not included, 3 were found to be ineligible after randomization (they were undergoing a second endoscopic procedure that day), and technical difficulties precluded patient participation in the other procedure. 


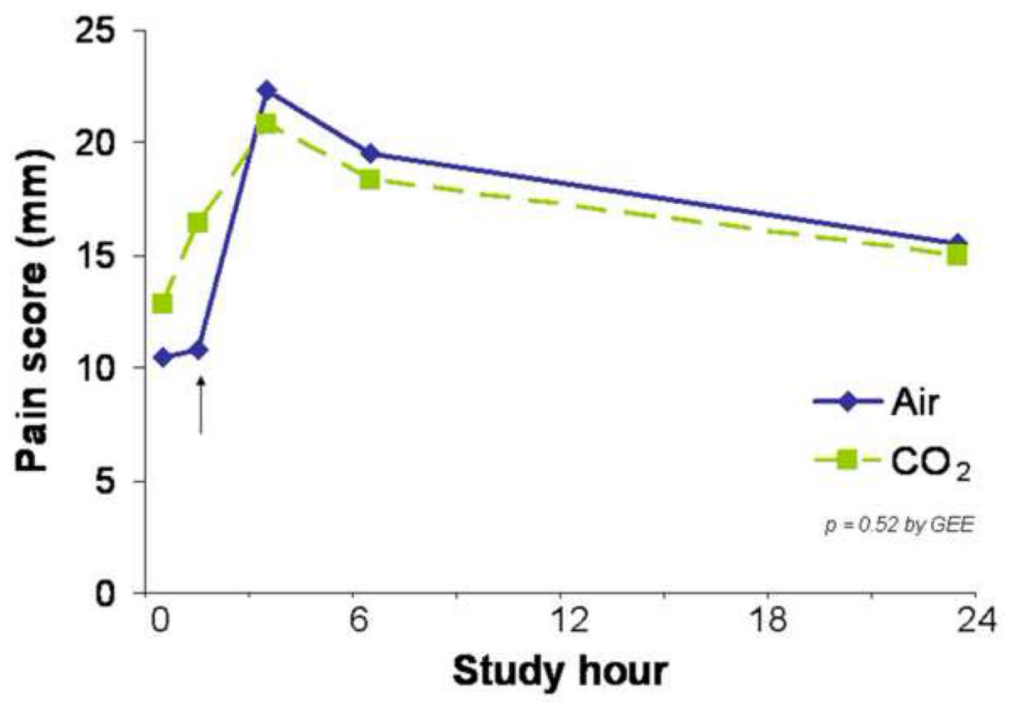

Figure 4.

Abdominal pain scores as measured on a 100 mm VAS before and 1, 3, 6, and 24-hours postERCP. The air insufflation group is in blue and the $\mathrm{CO}_{2}$ group is in green. The arrow points to the primary outcome at 1 hour post-procedure. As measured by GEE, there is no difference between pain scores over the time course of the study. 


\section{Table 1}

Characteristics of the study population

\begin{tabular}{|c|c|c|c|}
\hline Characteristic & $\begin{array}{l}\text { Air insufflation } \\
\quad(\mathbf{n}=\mathbf{3 8})\end{array}$ & $\begin{array}{c}\mathrm{CO}_{2} \text { insufflation } \\
(\mathbf{n}=36)\end{array}$ & p value \\
\hline Mean age (years (SD); range) & $59.7(16.6)(18-90)$ & $60.1(15.0)(26-84)$ & 0.90 \\
\hline Female (n, \%) & $18(47)$ & $18(50)$ & 0.82 \\
\hline \multicolumn{4}{|l|}{ Race (n, \%) } \\
\hline White & $27(71)$ & $26(72)$ & 0.56 \\
\hline African-American & $11(29)$ & $9(27)$ & \\
\hline Hispanic & $0(0)$ & $1(3)$ & \\
\hline Mean BMI $\left(\mathrm{kg} / \mathrm{m}^{2}(\mathrm{SD})\right.$; range $)$ & $27.4(7.2)(19-62)$ & $25.5(5.8)(17-44)$ & 0.21 \\
\hline \multicolumn{4}{|l|}{ Comorbidities (n, \%) } \\
\hline COPD & $2(5)$ & $3(8)$ & 0.60 \\
\hline Coronary artery disease & $5(13)$ & $6(17)$ & 0.67 \\
\hline Hypertension & $15(39)$ & $19(53)$ & 0.25 \\
\hline Diabetes & $11(29)$ & $11(31)$ & 0.88 \\
\hline Obstructive sleep apnea & $1(3)$ & $2(6)$ & 0.52 \\
\hline \multicolumn{4}{|l|}{ Previous surgeries (n, \%) } \\
\hline Any prior abdominal surgery & $24(63)$ & $22(61)$ & 0.86 \\
\hline Gastric (Heller; Nissen; etc) & $0(0)$ & $0(0)$ & -- \\
\hline Cholecystectomy & $15(39)$ & $14(39)$ & 0.96 \\
\hline Bowel resection & $2(5)$ & $3(8)$ & 0.60 \\
\hline Liver transplantation & $5(13)$ & $4(11)$ & 0.79 \\
\hline Hysterectomy & $5(13)$ & $4(11)$ & 0.79 \\
\hline Other $^{\dagger}$ & $8(21)$ & $4(11)$ & 0.25 \\
\hline Prior ERCP (n, \%) & $11(29)$ & $15(42)$ & 0.25 \\
\hline Prior sphincterotomy (n, \%) & $4(36)$ & $4(27)$ & 0.60 \\
\hline
\end{tabular}

Abbreviations: $\mathrm{BMI}=$ body mass index; $\mathrm{COPD}=$ chronic obstructive pulmonary disease

* By t-test for continuous variables and Chi-square (or Fisher's exact test) for categorical variables.

${ }^{\dagger}$ Other surgeries include: appendectomy (3), hernia repair (2), retroperitoneal mass resection, Roux-en-Y cyst-jejunostomy, pancreatic debridement, enterotomy repair during cholecystectomy, mesoatrial shunt, ovarian cystectomy, abdominal aortic aneurysm repair. 
Table 2

ERCP characteristics

\begin{tabular}{|c|c|c|c|}
\hline Characteristic & $\begin{array}{l}\text { Air insufflation } \\
\quad(n=38)\end{array}$ & $\begin{array}{c}\mathrm{CO}_{2} \text { insufflation } \\
(\mathrm{n}=36)\end{array}$ & p value \\
\hline \multicolumn{4}{|l|}{ ERCP main indication - general $(\mathrm{n}, \%)$} \\
\hline Biliary & $32(84)$ & $27(75)$ & 0.33 \\
\hline Pancreatic & $6(16)$ & $9(25)$ & \\
\hline \multicolumn{4}{|l|}{ ERCP all indications - detailed $(\mathrm{n}, \%)^{\dagger}$} \\
\hline Choledocholithiasis & $9(24)$ & $13(36)$ & 0.24 \\
\hline Pancreatitis & $5(13)$ & $8(22)$ & 0.31 \\
\hline Bile leak & $2(5)$ & $2(6)$ & 0.96 \\
\hline Jaundice & $1(3)$ & $1(3)$ & 0.97 \\
\hline Abnormal LFTs & $17(45)$ & $8(22)$ & 0.04 \\
\hline Mass & $2(5)$ & $4(11)$ & 0.36 \\
\hline Post-liver transplant evaluation & $5(13)$ & $4(11)$ & 0.79 \\
\hline Biliary stricture & $3(8)$ & $3(8)$ & 0.95 \\
\hline Question PSC & $4(11)$ & $3(8)$ & 0.75 \\
\hline Stent change & $3(8)$ & $7(19)$ & 0.15 \\
\hline Cholangitis & $3(8)$ & $1(3)$ & 0.33 \\
\hline Biliary dilation & $4(11)$ & $2(6)$ & 0.43 \\
\hline Choledochal cyst & $1(3)$ & $0(0)$ & 0.33 \\
\hline Fellow present in case $(\mathrm{n}, \%)$ & $34(89)$ & $33(92)$ & 0.75 \\
\hline Experience: fellow case number (mean (SD)) & $80.5(60.6)(1-199)$ & $88.8(59.7)(3-200)$ & 0.57 \\
\hline Sphincterotomy performed (n, \%) & $19(50)$ & $18(50)$ & 0.99 \\
\hline Stent placed (n, \%) & $13(34)$ & $7(19)$ & 0.15 \\
\hline \multicolumn{4}{|l|}{ Final diagnosis $(\%)$} \\
\hline Normal & $6(16)$ & $2(6)$ & 0.16 \\
\hline Choledocholithiasis & $8(21)$ & $15(42)$ & 0.06 \\
\hline Biliary sludge & $0(0)$ & $1(3)$ & 0.30 \\
\hline Pancreatitis & $3(8)$ & $4(11)$ & 0.64 \\
\hline Bile duct leak & $1(3)$ & $0(0)$ & 0.33 \\
\hline Pancreatic duct leak & $1(3)$ & $1(3)$ & 0.97 \\
\hline Mass & $2(5)$ & $4(11)$ & 0.36 \\
\hline Biliary stricture & $9(24)$ & $4(11)$ & 0.16 \\
\hline Cholangitis & $1(3)$ & $0(0)$ & 0.33 \\
\hline Ampullary stenosis & $2(5)$ & $0(0)$ & 0.16 \\
\hline PSC & $3(8)$ & $1(3)$ & 0.33 \\
\hline Stent change & $0(0)$ & $1(3)$ & 0.30 \\
\hline Aborted procedure & $1(3)$ & $2(6)$ & 0.52 \\
\hline Other ${ }^{+}$ & $1(3)$ & $1(3)$ & 0.97 \\
\hline
\end{tabular}

Abbreviations: $\mathrm{LFT}=$ liver function tests; $\mathrm{PSC}=$ primary sclerosing cholangitis

* By t-test for continuous variables and Chi-square (or Fisher's exact test) for categorical variables. 
${ }^{\dagger}$ Percentages total more than $100 \%$, as some patients had more than one ERCP indication.

\#Other final diagnoses include: stent migration into bile duct, and pancreatic stent migration out of the pancreatic duct. 
Table 3

Effects of air insufflation vs $\mathrm{CO}_{2}$

\begin{tabular}{|c|c|c|c|}
\hline Primary outcomes & $\begin{array}{l}\text { Air insufflation } \\
\quad(\mathbf{n}=\mathbf{3 8})\end{array}$ & $\begin{array}{c}\mathrm{CO}_{2} \text { insufflation } \\
\quad(\mathrm{n}=36)\end{array}$ & p value ${ }^{*}$ \\
\hline \multicolumn{4}{|l|}{ Mean abdominal pain scores (SD) } \\
\hline Prior to procedure & $10.5(21.0)$ & $12.8(19.6)$ & 0.63 \\
\hline 1-hr post procedure & $10.8(19.3)$ & $16.4(25.2)$ & 0.29 \\
\hline $3-\mathrm{hr} \operatorname{post}\left(\mathrm{n}_{\mathrm{Air}}=34 ; \mathrm{n}_{\mathrm{CO} 2}=32\right)$ & $22.3(27.8)$ & $20.8(32.2)$ & 0.95 \\
\hline $6-\mathrm{hr} \operatorname{post}\left(\mathrm{n}_{\mathrm{Air}}=34 ; \mathrm{n}_{\mathrm{CO} 2}=32\right)$ & $19.5(26.7)$ & $18.3(25.4)$ & 0.85 \\
\hline $24-\mathrm{hr}$ post $\left(\mathrm{n}_{\mathrm{Air}}=34 ; \mathrm{n}_{\mathrm{CO} 2}=32\right)$ & $15.5(24.0)$ & $15.0(24.7)$ & 0.94 \\
\hline \multicolumn{4}{|l|}{ Mean abdominal girth (cm) (SD) } \\
\hline Pre-procedure & $105.5(16.6)$ & $101.5(15.1)$ & 0.28 \\
\hline Post-procedure $\left(\mathrm{n}_{\mathrm{A}}=36 ; \mathrm{n}_{\mathrm{B}}=36\right)$ & $106.2(17.4)$ & $102.2(14.7)$ & 0.30 \\
\hline Change in abdominal girth $(\mathrm{cm})$ & $0.8(4.8)$ & $0.7(3.8)$ & 0.96 \\
\hline \multicolumn{4}{|l|}{ Secondary outcomes } \\
\hline \multicolumn{4}{|l|}{$\mathrm{CO}_{2}$ safety data (levels in $\mathrm{mmHg}$ ) } \\
\hline Mean baseline $\mathrm{CO}_{2}$ level (SD) & $40.5(6.2)$ & $40.3(4.6)$ & 0.89 \\
\hline Mean $\mathrm{CO}_{2}$ level (SD) & $46.1(8.8)$ & $45.2(5.7)$ & 0.61 \\
\hline Maximum $\mathrm{CO}_{2}$ level (mean (SD)) & $50.0(11.8)$ & $48.7(6.4)$ & 0.56 \\
\hline Mean change in $\mathrm{CO}_{2}$ level (SD) & $9.4(10.1)$ & $8.8(4.8)$ & 0.60 \\
\hline Mean fentanyl dose (mcg) (SD) & $162.2(58.6)$ & $155.6(66.8)$ & 0.65 \\
\hline Mean midazolam dose (mg) (SD) & $10.7(4.5)$ & $9.1(3.1)$ & 0.08 \\
\hline Promethazine used (n, \%) & $6(16)$ & $6(17)$ & 0.92 \\
\hline Mean promethazine dose (mg) (SD) & $25.0(0)$ & $17.0(6.2)$ & 0.01 \\
\hline Glucagon used (n, \%) & $22(58)$ & $24(67)$ & 0.44 \\
\hline Mean glucagon dose (mg) (SD) & $0.3(0.2)$ & $0.5(0.3)$ & 0.003 \\
\hline Mean cannulation time (mins) (SD) & $4.3(3.9)$ & $8.1(10.4)$ & 0.05 \\
\hline Cannulation success rate (n, \%) & $36(95)$ & $33(92)$ & 0.60 \\
\hline Mean total procedure time (mins) (SD) & $35.1(18.7)$ & $39.3(20.2)$ & 0.35 \\
\hline Mean recovery discharge time (mins) (SD) & $78.8(37.9)$ & $67.4(19.7)$ & 0.12 \\
\hline Mean procedure cost (dollars) (SD) & $7000(2560)$ & $7170(2200)$ & 0.76 \\
\hline Mean equipment costs & $2000(1390)$ & $1860(1340)$ & 0.67 \\
\hline Mean radiology costs & $94(42)$ & $96(36)$ & 0.83 \\
\hline Mean hospital costs & $2420(550)$ & $2570(320)$ & 0.14 \\
\hline Mean physician costs & $2490(1350)$ & $2630(1070)$ & 0.63 \\
\hline \multicolumn{4}{|l|}{ Complications $(\mathrm{n}, \%)^{\dagger}$} \\
\hline Patients with any complication & $13(34)$ & $5(14)$ & $0.04^{\dagger \dagger}$ \\
\hline Respiratory depression & $2(5)$ & $0(0)$ & 0.16 \\
\hline $\mathrm{CO}_{2}$ retention (max level $\left.>45\right)$ & $22(58)$ & $25(69)$ & 0.30 \\
\hline $\mathrm{CO}_{2}$ retention $(\max$ level $>50)$ & $18(47)$ & $15(42)$ & 0.62 \\
\hline
\end{tabular}




\begin{tabular}{|c|c|c|c|}
\hline Primary outcomes & $\begin{array}{l}\text { Air insufflation } \\
\quad(\mathbf{n}=\mathbf{3 8})\end{array}$ & $\begin{array}{l}\mathrm{CO}_{2} \text { insufflation } \\
\quad(\mathrm{n}=36)\end{array}$ & p value ${ }^{*}$ \\
\hline $\mathrm{CO}_{2}$ retention $(\max \text { level }>55)^{\frac{f}{t}}$ & $8(22)$ & $5(15)$ & 0.49 \\
\hline Hypotension & $0(0)$ & $0(0)$ & -- \\
\hline Cardiac arrhythmia (brady to 52$)^{\#}$ & $1(3)$ & $0(0)$ & 0.33 \\
\hline Immediate bleeding & $0(0)$ & $0(0)$ & -- \\
\hline Delayed bleeding & $0(0)$ & $0(0)$ & -- \\
\hline Cholangitis & $0(0)$ & $0(0)$ & -- \\
\hline Pancreatitis & $2(5)$ & $1(3)$ & 0.57 \\
\hline Perforation & $0(0)$ & $0(0)$ & -- \\
\hline Death & $0(0)$ & $0(0)$ & -- \\
\hline Other $^{* *}$ & $3(8)$ & $0(0)$ & 0.08 \\
\hline \multicolumn{4}{|c|}{ By t-test for continuous variables and Chi-square (or Fisher's exact test) for categorical variables. } \\
\hline \multicolumn{4}{|c|}{ Complications total more than 13 because several patients have more than one event. } \\
\hline \multicolumn{4}{|c|}{ Only $\mathrm{CO}_{2}>55$ was considered a complication. } \\
\hline \multicolumn{4}{|c|}{ \# The arrhythmia was bradycardia to a nadir of 52 beats per minute; no atropine administered. } \\
\hline \multicolumn{4}{|c|}{$\begin{array}{l}\text { ** Other complications include: one patient fell in recovery and bumped head but had no injury; one patient had a post-procedure fever, was admitted } \\
\text { and observed for } 24 \text { hours, but had no localizing infection and the fever resolved; and one patient had post-procedure abdominal pain, was admitted } \\
\text { and observed for } 24 \text { hours, but had no structural cause of the pain, which subsequently resolved. }\end{array}$} \\
\hline
\end{tabular}

